\title{
Building Information Modelling (BIM) Contribution towards Sustainability: Awareness of Malaysian Contractors
}

\author{
Syed Zakaria Sharifah Akmam ${ }^{1}$, Abdul Rahim Nur Soleha ${ }^{2 *}$ \\ ${ }^{1}$ Senior lecturer, School of Civil Engineering, Universiti Sains Malaysia, Penang, Malaysia. \\ ${ }^{2}$ Postgraduate student, School of Civil Engineering, Universiti Sains Malaysia, Penang, Malaysia. \\ *Email: nursoleha88@yahoo.com
}

\begin{abstract}
Building Information Modelling (BIM) has become an attention-grabbing topic among researchers and industry players around the world including Malaysia. As the construction industry always plaguing with issues related to massive waste generated from construction and demolition process, encouraging BIM implementation is considered as one of the available technology-based alternatives to encounter these issues. BIM is a type of technology that offers the development of construction project before the real construction process, which allows the identification of any issues earlier, throughout the design and planning phases. Currently, numerous researches have been focusing on the benefits offered by BIM to the construction industry. However, there are still several construction players who lack awareness of BIM's contribution, especially towards sustainability. The purpose of this paper is to explore the awareness of contractors in Malaysia on the contribution of BIM towards sustainability, namely economic, environmental and social. A total of 133 contractors from grade G1 to G7 were involved in a survey. The results revealed that majority of the respondents were aware on BIM contributions towards environmental sustainability, besides other two sustainability pillars, economic and social. Thereby, there is a need to educate and provide realistic information to the construction industry stakeholders, as a process to create a better understanding and wider exposure, and to convince them to implement BIM technology.
\end{abstract}

Keywords: Awareness, Building Information Modelling, Contractors, Malaysian Construction Industry, Sustainability

\subsection{INTRODUCTION}

Building Information Modeling (BIM) is the latest innovation, which involves virtual designs and other construction activities in an integrated approach. The existence of BIM in the construction industry brings great advantages towards reducing potential issues during design and construction processes as well as the whole project life-cycle ( $\mathrm{Li}$ et al., 2014). As Malaysia is moving towards achieving its vision to become high-income economy (Malaysia Productivity Corporation [MPC], 2017), leverage on information technology (IT), in this context is BIM, is perceived as essential to driving this transformation. Implementation of technology and modern practices in the construction industry has been highlighted in the 11th Malaysia Plan (MP) (11th Malaysia Plan, 2015) as well as the Construction Industry Transformation Programme (CITP) (CITP, 2015) to accelerate the momentum of economic growth.

BIM is also considered as one of the technologies that help in improving sustainable performance during a project's lifecycle to achieve sustainable infrastructure development. Lifecycle 
process of a project includes planning, design, construction, operation and maintenance, and demolition (Chong et al., 2017). In the lifecycle process, the construction phase has been identified as a major contributor affecting the sustainable performance of construction projects (Enshassi et al., 2016). In this regard, the construction players are encouraged to consider sustainability aspects in construction projects to avoid any excessive exploitation of natural resources and to protect the environment without compromising the needs of future young generations. In order to fully understand the industry's awareness on sustainability and BIM as a whole, this study was performed to determine the current level of BIM awareness with some consideration om BIM contribution towards sustainability aspect.

\subsection{LITERATURE REVIEW}

\subsection{Sustainable Construction}

Sustainable construction can be referred as "the capability of the industry players to produce buildings or structures that sustain the environment, enhances the quality of life and generates long term wealth" (Le et al., 2012). It has become a vital cornerstone for securing long-term environmental, economic and social viability. The construction industry is always been associated with the issues related to cost overrun (Abdul Rahman et al., 2013), delay (Memon et al., 2014a) and massive waste production (Kamar and Hamid, 2012). These issues are usually interrelated with each other. For example, an extra waste produced due to the changes in design during the construction process can cause the increment of the project's cost and affecting the project's schedule.

As compared to other construction projects, buildings have the greatest capacity to make a major contribution to a more sustainable future for our planet. Buildings account for more than forty per cent $(40 \%)$ of energy consumption and seventy per cent $(70 \%)$ of all timber as well as a considerable proportion of raw materials globally (Thilakaratne and Lew, 2011). It is also generated a significant amount of wastes over their lifecycle (incorporating raw material production, construction, operation and demolition processes) (Nguyen and Gray, 2016).

Construction waste is produced either from material or non-value-adding activities during the construction process (Ismail and Yusof, 2015). Mostly, non-value-added activities happen when there is a lack of communication at the design stage and this situation will affect other project life-cycle. Seven non-value-added activities contribute to waste production, defect, overproduction, unnecessary inventory, inappropriate processing, transportation, unnecessary motion and waiting time. Eliminating these wastes will give a significant impact on the cost and time of the project. Therefore, to develop a sustainable construction, effective decisions need to be made earlier at the design and preconstruction stages to access the building performance, including building's form (orientation, massing envelope and daylighting), materials, contexts and technical system (Azhar et al., 2009).

\subsection{Building Information Modeling (BIM)}

Over the last two or three decades, the developments of computer-aided design software and building information modelling (BIM) have changed the traditional design formats and communication patterns of the AEC sector. The United States has the highest percentage of contractors that implemented BIM in the year 2015 followed by Brazil, Germany, Australia, France and the UK. In this regard, Brazil shows the increment of 3 times (73\%) as compared to the year 2013 (24\%). However, in Malaysia, the government has just started to encourage construction-related 
companies to implement BIM in their projects. At the moment, BIM implementation in Malaysia is still very low (Memon et al., 2014b) where BIM level is between Level 0 and 1 (Zakaria et al., 2013).

Strategy and knowledge about BIM are significant to educate the industry players to implement BIM as many of them believe that new technology is difficult to learn and could increase the operating cost. In fact, there are many benefits offered by BIM particularly on sustainability aspects, namely environmental, economic and social. Many researchers have conducted surveys on the benefits of BIM and highlighted the improvement in quality, time and cost of overall project performance. However, the exploration of the awareness and knowledge of the construction industry players on BIM benefits towards sustainability pillars is still lacking.

For example, BIM would enable users to check any design conflicts in the project (Zhang and Gao, 2013) to reduce errors and omission as well as rework before the construction phase. The reduction of rework itself can contribute to the sustainability aspects. In the context of environmental sustainability, reducing rework leading to the reduction of waste in a construction site (Liu et al., 2015). Apart from that, reducing rework could also lead to the saving of thousands dollars (Zhang and Gao, 2013) which lead to economic sustainability. It can also enhance safety in construction site (Rajendran and Clarke, 2011) as there shall be lesser presence and exposure for workers as well as the surrounding population's towards any possible accidents, which then lead to the better social sustainability aspect.

There is a need to highlight on each interconnection of BIM's benefits towards sustainability aspects to allow a better understanding of BIM and encourage its development in the construction industry. Therefore, this research aims to address this gap and provide some contribution to knowledge, particularly in the civil engineering and construction management area.

\subsection{METHODOLOGY}

Initially, the questionnaire survey was conducted on a random basis amongst 300 selected contractors Grade 7 (G7) in Malaysia through a postal mail survey. Poor responses were received probably due to the lack of organisation's interest in topics related to BIM and the survey generated a sample of 35 responses. Due to the small number of responses, a decision was made to continue with another approach. The questionnaire survey was distributed to potential respondents during a series of BIM awareness programmes organised by (CIDB) Malaysia. This phase of data collection has obtained a greater response rate. Thus, the total number of 133 responses were gathered through both approaches. The respondents are required to express the frequency of considering sustainability aspects in construction projects and their awareness of BIM innovation. Table 1 and Figure 1 shows the background of the respondents and Table 2 presents the organisation's information.

Table 1: Respondents Background

\begin{tabular}{|c|c|c|c|c|c|c|c|c|c|c|c|c|c|}
\hline \multicolumn{3}{|c|}{ Gender } & \multicolumn{5}{|c|}{ Working Experience } & \multicolumn{6}{|c|}{ Academic Qualification } \\
\hline Male & Female & $\begin{array}{c}\mathrm{N} / \\
\mathrm{A}\end{array}$ & $<5 y$ & $5-10$ & $11-15$ & $\begin{array}{c}>15 \\
\mathrm{y}\end{array}$ & $\begin{array}{c}\mathrm{N} / \\
\mathrm{A}\end{array}$ & Ph.D & Msc & Degree & Diploma & Other & $\begin{array}{l}\mathrm{N} \\
/ \\
\mathrm{A}\end{array}$ \\
\hline 74 & 57 & 2 & 46 & 33 & 21 & 31 & 2 & 2 & 11 & 58 & 34 & 26 & 2 \\
\hline
\end{tabular}

*N/A: Not Available 


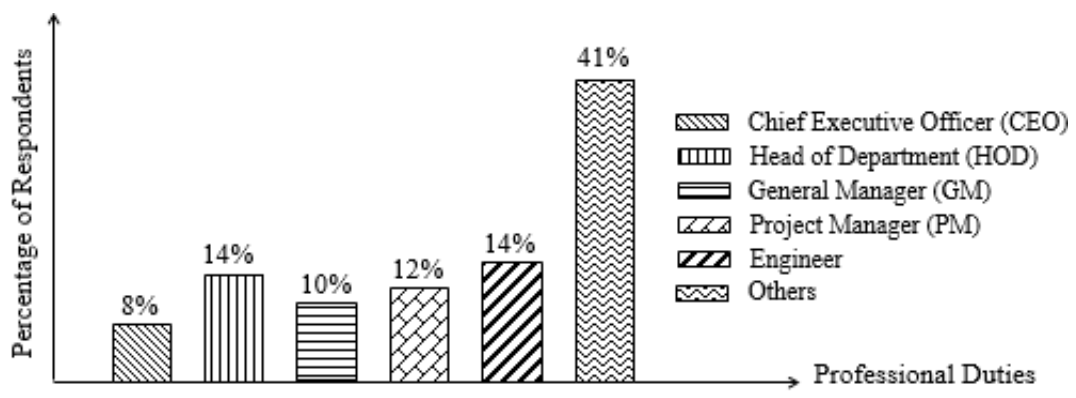

Figure 1: Professional Duties of Respondents

Table 2: Organisations Information

\begin{tabular}{|c|c|c|c|c|c|c|c|}
\hline \multicolumn{3}{|c|}{ CIDB's Grade } & \multicolumn{5}{c|}{ Size of Organisation (No. of employees) } \\
\hline G7 & G1-G6 & N/A & $<50$ & $50-150$ & $150-500$ & $>500$ & N/A \\
\hline 80 & 51 & 2 & 94 & 27 & 7 & 4 & 1 \\
\hline
\end{tabular}

*N/A: Not Available

The questions were designed to determine the regularity of participating organisations in considering sustainability aspects in the life cycle of construction projects. Apart from that, the respondents were also required to rank the sustainability aspect, namely economic, social and environmental that need more consideration from most important to less important when constructing a project. The questions also incorporate the benefits of BIM-based on the use and potential impact of BIM implementation that were perceived to contribute to the sustainability aspect. The respondents were required to choose the benefit of BIM innovation that they perceived as how they could contribute to each aspect of sustainability. For the analyses, the benefits selected by more than $50 \%$ of respondents were considered or categorised under that sustainability aspects.

\subsection{RESULTS AND DISCUSSION}

In relation to determining the organisation's consideration in a truly sustainable construction project, the findings discovered that majority of the respondents were considering the sustainability aspect in their projects as illustrated in Figure 2. However, seven (7) respondents could not provide the information on this question probably due to the lack of understanding of the meaning of sustainability.

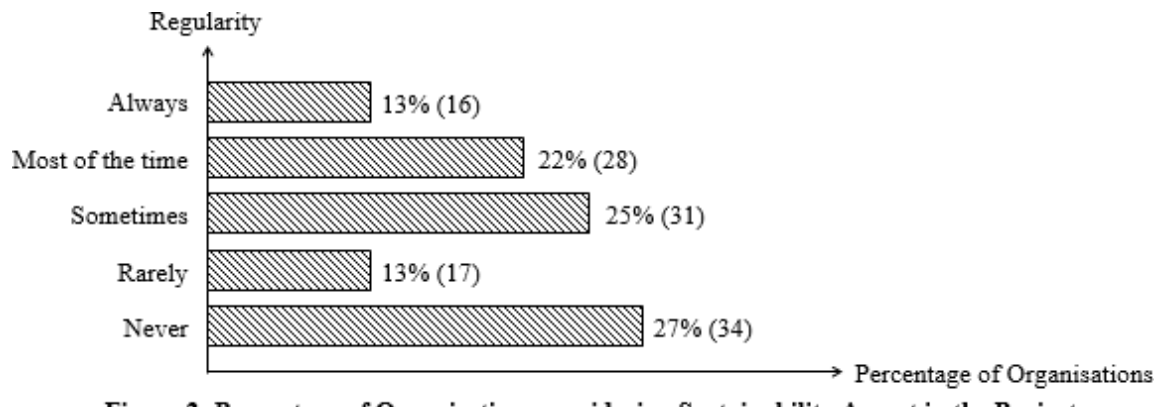

Figure 2: Percentage of Organisations considering Sustainability Aspect in the Project

In order to further analyse the importance of each organisation towards the sustainability aspect, the respondents were required to provide information on the number of projects that their organisation have obtained a green building certification. The results show that only 35 organisations 
have received green building certifications in at least one of the organisation's project. This indicates that there is still a lack of readiness for some organisations, especially in the Malaysian construction industry in developing a sustainable construction.

The respondents were also required to express their point of view on the ranking of which sustainability aspect that needs more consideration in project development. Based on the findings, savings on construction cost was perceived as the most top priority for the construction stakeholders when constructing a project as compared to producing a better quality of end-product and reducing impact towards the environment as illustrated in Figure 3. This is usually to fulfil the client's objective on the needs to complete the project within the allocated time and budget (Harun, 2017). Therefore, developing a construction project to minimise the construction cost is the priority of surveyed organisations as compared to reducing impacts on environmental and provide a better quality of life to the end-consumers.

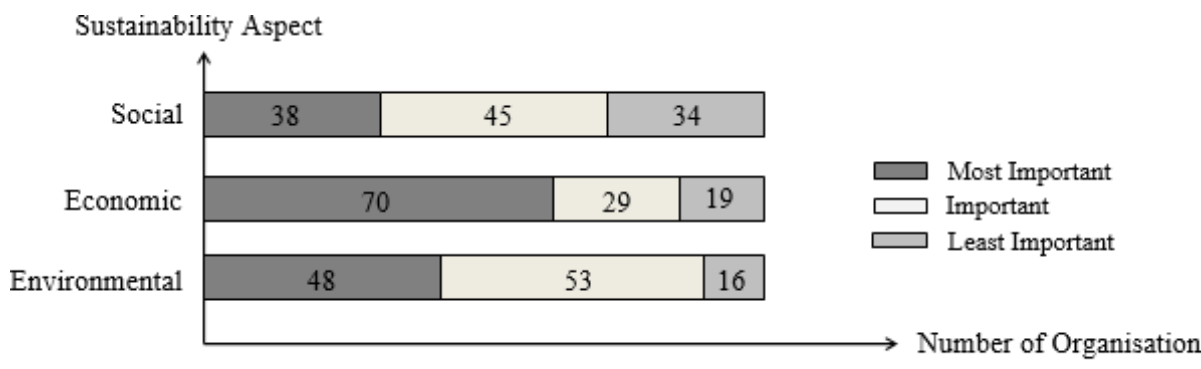

Figure 3: Number of Organisations for Each Sustainability Aspect

In order to measure the awareness of organisations on BIM contribution towards sustainability, there is a need to understand the awareness of organisations on BIM in general. The findings revealed that only 107 organisations were aware of BIM. This situation is basically due to the reasons that the other remaining 26 organisations were not possessed any BIM knowledge or not aware of the government encouragement towards the implementation of BIM. According to the latest survey conducted by CIDB (Hamid et al., 2017), the majority of the construction industry stakeholders are aware of BIM and actions have been taken to align with the national agenda. However, to analyse the sustainability aspects of BIM implementation, only 56 organisation with the least knowledge of BIM was considered.

Technically, most of the benefits offered by BIM could contribute to economic, environmental and social sustainability. However, lack of awareness and knowledge has hindered the exploration of BIM benefits towards sustainability aspects. For example, a majority (78\%) of the respondents realised that the benefits of BIM were meant to "perform design visualisation" that would contribute to the environmental sustainability, compared to $47 \%$ for economic and $36 \%$ for social sustainability. Performing visualisation in a construction project could contribute to all pillars of sustainability as illustrated in Figure 4. This is possibly due to the limited knowledge of BIM related to sustainability. 


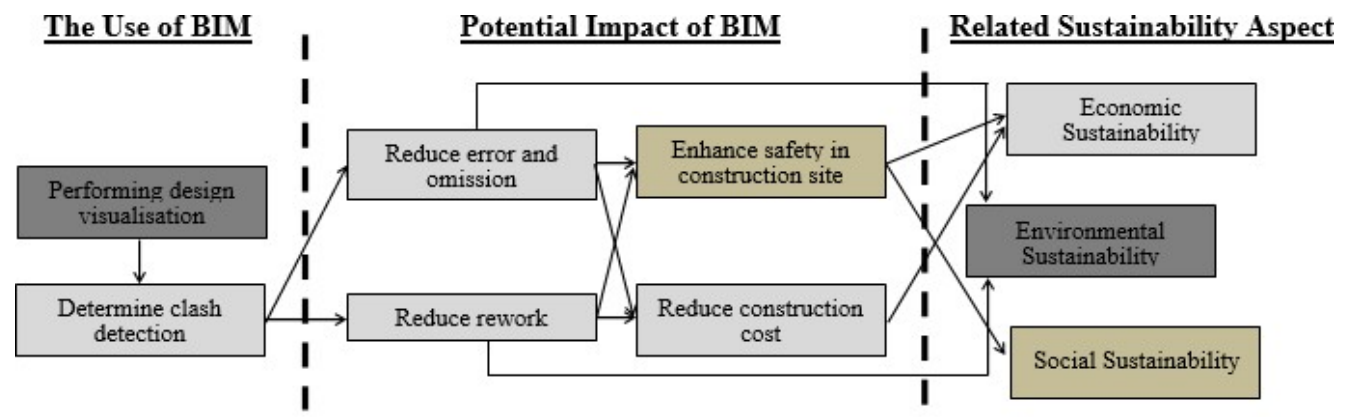

Figure 4: Example: Contribution of BIM's Benefits towards Sustainability Aspect

Through 3D visualization, a better understanding of project owners on the development of the project will reduce the possibility of on-site changes, thus, leading to the reduction of waste in a construction site (Liu et al., 2015). With the help of visualisation feature of BIM, any clashes and conflicts in design can be identified and observed from the model (Nadeem et al., 2018). The process of finding the clashes in models is known as clash detection (Bhagwat and Shinde, 2016). Clash detection helps in identifying errors and mistakes as well as any possible constructability issues which potentially contributes to the occurrence of the change order and rework (Ibrahim et al., 2019) which indirectly affect the original plan and resulting to the additional project time and extra cost.

A study by Fan et al. (2014) was performed to capture the effect of BIM during the construction phase and one of the results shows that the owners believed that change of orders could save $4-7 \%$ of project cost, thus, lead to economic sustainability. Rework will not only produce construction waste but also influence the quality of work and workers' productivity at the construction site, which probably may increase the chances of incidents and injuries. Therefore, having a project with less rework provides a better and safe environment (Rajendran and Clarke, 2011) and reduce the potential of project delays, thus, lead to social sustainability.

However, based on Figure 4, the majority of the respondents were only aware of "performing design visualisation" could contribute to environmental sustainability. Meanwhile, the use of BIM to "determine clash detection" and the potential impact of BIM towards "reduce errors and omissions", "reduce rework", and "reduce construction cost" were only contributed to economic sustainability. Apart from that, most of the respondents were aware that safety enhancement in a construction site was only meant for social sustainability. Table 3 and Table 4 show the percentage of respondents who perceived each of the benefits of BIM towards sustainability aspect.

Table 3: The Use of BIM Innovation from the Perspective of Sustainability Aspect

\begin{tabular}{|l|c|c|c|}
\hline \multicolumn{1}{|c|}{ The Use of BIM Innovation } & Economic & Environmental & Social \\
\hline Determine clash detection & $\mathbf{6 7 \%}$ & $\mathbf{5 3 \%}$ & $50 \%$ \\
\hline Performing design visualisation & $47 \%$ & $\mathbf{7 8 \%}$ & $36 \%$ \\
\hline Designing site and logistics management & $47 \%$ & $\mathbf{5 3 \%}$ & $39 \%$ \\
\hline Selecting building's orientation & $28 \%$ & $\mathbf{5 8 \%}$ & $28 \%$ \\
\hline Modeling building energy performance & $47 \%$ & $\mathbf{8 3 \%}$ & $44 \%$ \\
\hline Selecting sustainable material & $\mathbf{6 2 \%}$ & $\mathbf{7 2 \%}$ & $31 \%$ \\
\hline Conducting daylight analysis & $28 \%$ & $\mathbf{5 6 \%}$ & $33 \%$ \\
\hline Designing assistance and constructability & $50 \%$ & $42 \%$ & $50 \%$ \\
\hline Total Majority & 2 & 7 & 0 \\
\hline
\end{tabular}


Table 4: The Potential Impact of BIM Innovation from the Perspective of Sustainability Aspect

\begin{tabular}{|l|c|c|c|}
\hline \multicolumn{1}{|c|}{ Potential Impact of BIM Innovation } & Economic & Environmental & Social \\
\hline Reduce rework & $\mathbf{9 2 \%}$ & $50 \%$ & $44 \%$ \\
\hline Improved collaboration & $42 \%$ & $\mathbf{5 6 \%}$ & $50 \%$ \\
\hline Reduce errors and omissions & $\mathbf{9 2 \%}$ & $\mathbf{6 1 \%}$ & $31 \%$ \\
\hline Better scheduling and sequencing & $\mathbf{5 8 \%}$ & $42 \%$ & $50 \%$ \\
\hline Reduce overall project duration & $\mathbf{6 1 \%}$ & $\mathbf{5 3 \%}$ & $50 \%$ \\
\hline Increase labour productivity & $50 \%$ & $28 \%$ & $\mathbf{5 3 \%}$ \\
\hline Reduce construction cost & $\mathbf{7 5 \%}$ & $50 \%$ & $42 \%$ \\
\hline Enhance safety in construction site & $33 \%$ & $\mathbf{5 3 \%}$ & $\mathbf{5 6 \%}$ \\
\hline Better cost control/ predictability & $\mathbf{9 2 \%}$ & $\mathbf{5 6 \%}$ & $28 \%$ \\
\hline Improved drawing coordination & $47 \%$ & $\mathbf{5 3 \%}$ & $31 \%$ \\
\hline Collaborating with owners/ design firms & $31 \%$ & $36 \%$ & $44 \%$ \\
\hline Total Majority & 6 & 6 & 2 \\
\hline
\end{tabular}

The summary of the results is shown in Figure 5. This result indicates that currently, the majority of the construction players were aware that BIM innovations contributed towards environmental sustainability and less awareness or knowledge on BIM contributed towards economic and social sustainability. Therefore, it is important to educate and convince all stakeholders on the contribution of each benefit of BIM towards sustainability aspect, with the anticipation of an increase in BIM development.

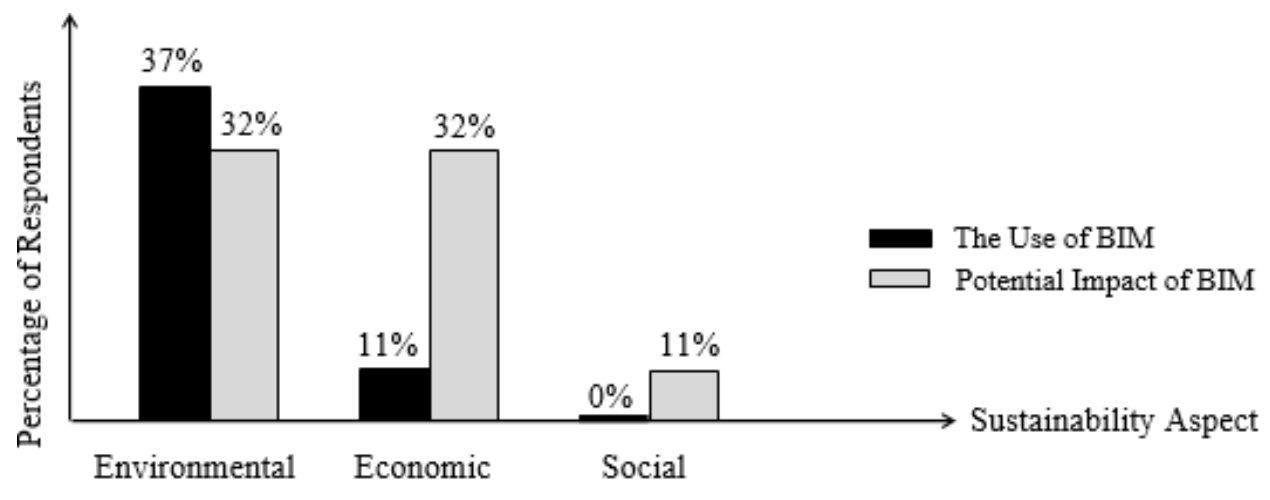

Figure 5: Respondents Awareness on the Contribution of BIM towards Sustainability Aspect

Although the respondents' perception towards the use of BIM varied from the perspectives of environmental, economic and social aspects, their awareness on the potential impact of BIM can be considered as encouraging. This situation reflects that to a certain extent, the construction stakeholders have a sound knowledge and awareness on BIM implementation that support its implementation in the future for sustainable development.

\subsection{CONCLUSION}

BIM can be considered as one of the technologies that help in improving sustainable performance during construction lifecycle to achieve sustainable infrastructure development. Despite most of the BIM benefits that contributed to sustainability aspects, the awareness of BIM contribution towards sustainability is still lacking among the construction players. In this context, disseminating 
information on the capability of BIM towards sustainability is perceived as necessary to increase the awareness and knowledge of the construction industry stakeholders on BIM innovation. The findings revealed that some of the respondents weren't aware of the benefits of BIM towards all three sustainability aspect, namely environmental, economic and social. However, majority of the respondents were still considering BIM as an innovation that assists in project development with less impact towards the surrounding environment. Therefore, there is a need to improve the content of the current seminar or programme related to BIM to incorporate the benefits of BIM towards sustainability with the anticipation of an increase in BIM development.

\subsection{ACKNOWLEDGEMENTS}

This study was supported by the School of Civil Engineering, Engineering Campus, Universiti Sains Malaysia. The authors appreciate the contributions of the organisations involved in the data collection process.

\subsection{REFERENCE}

1. Abdul Rahman, I., Memon, A. H., Karim, A. \& Tarmizi, A. (2013). Significant factors causing cost overruns in large construction projects in Malaysia. Journal of Applied Science, $13,286-293$.

2. Azhar, S., Brown, J. \& Farooqui,(2009) R. BIM-based sustainability analysis: An evaluation of building performance analysis software. Proceedings of the 45th ASC annual conference, 2009. 90-93.

3. Bhagwat, P. \& Shinde, R. (2016). Clash detection-A new tool in project management. International Journal of Scientific Research in Science, Engineering and Technology, 2, 193197.

4. Chong, H.-Y., Lee, C.-Y. \& Wang, X. (2017). A mixed review of the adoption of Building Information Modelling (BIM) for sustainability. Journal of cleaner production, 142, 41144126.

5. Construction Industry Development Board Malaysia (CIDB) 2015. Construction Industry Transformation Programme 2016-2020.

6. Economic Planning Unit Malaysia (EPU) 2015. Eleventh Malaysia Plan 2016- 2020: Anchoring Growth on People, Kuala Lumpur.

7. Enshassi, A., Kochendoerfer, B. \& Al Ghoul, H. (2016.) Factors Affecting Sustainable Performance of Construction Projects during Project Life Cycle Phases. International Journal of Sustainable Construction Engineering and Technology, 7, 50-68.

8. Fan, S.-L., Skibniewski, M. J. \& Hung, T. W. (2014). Effects of Building Information Modeling During Construction. Journal of Applied Science and Engineering, 17, 157-166.

9. Hamid, I. D. Z. A., Roslan, A. F., Fasc, Zain, M. Z. M., Kilau, N. M., Dzulkalnine, N. \& Hussain, D. A. H. (2017). Building Information Modeling (BIM) Stage 2 Implementation Strategy for The Construction Industry in Malaysia. E-Construct Building Information Modelling Magazine. Kuala Lumpur: MyBIM Centre. 
10. Harun, A. A. (2017). Element-element kritikal pengurusan perubahan di peringkat rekabentuk projek pembinaan. Masters, Universiti Teknologi Malaysia (UTM).

11. Ibrahim, H. S., Hashim, N. \& Jamal, K. A. A. (2019) The Potential Benefits of Building Information Modelling (BIM) in Construction Industry. IOP Conference Series: Earth and Environmental Science, 2019. IOP Publishing, 012047.

12. Ismail, H. \& Yusof, Z. M. (2015). Waste as Challenges in the Construction Industries.

13. Kamar, K. A. M. \& Hamid, Z. A. (2012). Sustainable construction and green building: the case of Malaysia. WIT Transactions on Ecology and The Environment, 167.

14. Le, T. T., Goodier, C. I., Pham, H. H., Soutsos, M. N. \& Tong, K. T. (2012). Sustainable Construction - An International Comparison of Civil Engineering Students. Journal of Civil Engineering and Architecture 6, 1648 - 1653.

15. Li, J., Wang, Y., Wang, X., Luo, H., Kang, S.-C., Wang, J., Guo, J. \& Jiao, Y. (2014). Benefits of Building Information Modelling in the Project Lifecycle: Construction Projects in Asia. International Journal of Advanced Robotic Systems.

16. Liu, Z., Osmani, M., Demian, P. \& Baldwin, A. (2015). A BIM-aided construction waste minimisation framework. Automation in construction, 59, 1-23.

17. Malaysia Productivity Corporation (MPC) (2017). Productivity Report 2016/2017. Productivity Performance of the Construction Sector. Kuala Lumpur.

18. Memon, A. H., Rahman, I. A., Akram, M. \& Ali, N. M. (2014a) . Significant factors causing time overrun in construction projects of Peninsular Malaysia. Modern Applied Science, 8, 16.

19. Memon, A. H., Rahman, I. H., Memon, I. \& Azman, N. I. A. (2014b). BIM in Malaysian Construction Industry: Status, Advantages, Barriers and Strategies to Enhance the Implementation Level. Research Journal of Applied Sciences, Engineering and Technology, $8,606-614$.

20. Nadeem, A., Wong, A., Akhanova, G., Azhar, S. \& Wong, S. (2018). Application of building information modeling (BIM) in site management-material and progress control. Proceedings of the 21st International Symposium on Advancement of Construction Management and Real Estate, 2018. Springer, 289-297.

21. Nguyen, H.-T. \& Gray, M. (2016). A Review on Green Building in Vietnam. Procedia Engineering, 142, 314-321.

22. Rajendran, S. \& Clarke, B. (2011). Building Information Modeling: safety benefits \& opportunities. Professional Safety, 56, 44-51.

23. Thilakaratne, R. \& Lew, V. (2011). Is LEED leading Asia?: an analysis of global adaptation and trends. Procedia engineering, 21, 1136-1144. 
e-issn: $2229-8568$

24. Zakaria, Z., Mohamed Ali, N., Haron, A. T., Marshall-Ponting, A. \& Abd Hamid, Z. (2013). Exploring the adoption of Building Information Modelling (BIM) in the Malaysian construction industry: A qualitative approach. International Journal of Research in Engineering and Technology, 2, 384-395.

25. Zhang, D. \& Gao, Z. (2013). Project Time and Cost Control Using Building Information Modeling. ICCREM 2013. American Society of Civil Engineers. 